\title{
Factors Affecting Artificial Insemination Pregnancy Outcome
}

\author{
Xue Wang* \\ Yue Zhang* \\ Hong-Liang Sun \\ Li-Ting Wang \\ Xue-Feng Li \\ Fei Wang \\ Yan-Lin Wang \\ Qing-Chun Li
}

Department of Reproductive Medicine, Binzhou Medical University Hospital, Binzhou, 256603, People's Republic of China

*These authors contributed equally to this work
Correspondence: Qing-Chun Li; Yan-Lin Wang

Department of Reproductive Medicine, Binzhou Medical University Hospital, No. 66I Huanghe 2nd Road, Binzhou, 256603, People's Republic of China

Tel +8654332587I5; +865433258713

Fax +865433257792

Email qingchunli_doc@163.com;

docylwang2003@I63.com
Objective: The aim of the present study was to explore related clinical pregnancy outcome factors in intrauterine insemination (IUI).

Materials and Methods: The clinical data of 3984 IUI cycles in 1862 couples experiencing infertility who attended the Reproductive Center of Binzhou Medical University Hospital between July 2006 and July 2017 were retrospectively analyzed. Female and male patient age, endometrial thickness (EMT), the post-wash total motile sperm count (PTMC), artificial insemination timing, insemination frequency, and ovarian stimulation protocols were compared between the study's pregnant group and non-pregnant group in order to explore any correlation.

Results: There were statistically significant differences in female and male age, EMT, artificial insemination timing, insemination frequency, and ovarian stimulation protocols between the two groups $(\mathrm{p}<0.05)$. The clinical pregnancy rate was significantly higher in ovarian stimulation cycles than in natural cycles $(21.2 \%$ and $11.6 \%$, respectively; $p<0.01)$, the clinical pregnancy rate was significantly higher in double IUI than in single IUI $(17.8 \%$ and $12.1 \%$, respectively; $p<0.01$, and EMT was significantly greater in the pregnant group than in the control group $(\mathrm{p}<0.05)$. However, the differences in clinical pregnancy rates among the PTMC groups were not statistically significant $(14.8 \%, 14.4 \%, 17.3 \%$, and $17.3 \%$, respectively; $\mathrm{p}>0.05$ ).

Conclusion: The results of the present study demonstrate that the clinical IUI pregnancy rate is correlated with the factors of female age, male age, EMT, artificial insemination timing, insemination frequency, and ovarian stimulation protocols; the ovarian stimulation protocol can noticeably improve the patient pregnancy outcome. Furthermore, compared with single IUI, double IUI can significantly increase the clinical pregnancy rate.

Keywords: intrauterine insemination, clinical pregnancy rate, post-wash total motile sperm count, ovarian stimulation cycle, timing of intrauterine insemination

\section{Introduction}

Intrauterine insemination (IUI) is a type of assisted reproductive technology (ART) that increases the conception rate in cases of both male and female infertility. It refers to the in vitro transcervical injection of washed spermatozoa into a woman's uterine cavity ${ }^{1}$ and is used to treat infertility induced by moderate male factors, endometriosis, ovulation failure, and unexplained factors. ${ }^{2,3}$ Compared with $^{2}$ in vitro fertilization (IVF)/intracytoplasmic sperm injection (ICSI), IUI is a simpler, safer, and cheaper treatment protocol with a lower complication rate; this makes it more easily accepted by patients experiencing infertility. ${ }^{1,4-6}$ Due to many factors, the clinical IUI pregnancy rate is also lower than the rates of other 
ARTs. ${ }^{4,5}$ It is well known that there are inconsistencies among reports in literature on IUI influencing factors. The present study reviews the different influencing factors of 3984 cycles in 1862 couples experiencing infertility who underwent an IUI at the Reproductive Center of Binzhou Medical University Hospital between July 2006 and July 2017, such as different female and male age stages, endometrial thickness (EMT), forward-moving sperm number, artificial insemination timing, IUI times/cycles, different treatment protocols, and uses of different ovulation-stimulating drugs. The aim of the analysis of the data obtained from the center is to provide a reference for clinical decision-making. The limitation of the study is that the data has been collected from a single center; furthermore, some data may be offset.

\section{Materials and Methods Research Object}

A total of 3984 IUI cycles in 1862 couples experiencing infertility who attended the Reproductive Center of Binzhou Medical University Hospital between July 2006 and July 2017 were included in the present study. This study was conducted in accordance with the Declaration of Helsinki, and the study protocol was approved by the ethics committee of Binzhou Medical University Hospital, China (No. 2019-LW-030), and all methods were performed in accordance with the approved guidelines. This study only involves the collection or study of existing data, documents, and records, and these sources were publicly available and could not be used to identify subjects either directly or by subject-related identifiers, thus exempting informed consent.

\section{Inclusion Criteria}

Female patients were confirmed with at least one unobstructed fallopian tube. This confirmation was conducted during the hydrotubation examination via hysterosalpingography, hysteroscopy, laparoscopy, or laparotomy. In addition, the couples included in the present study had a normal sexual life without contraception for at least one year.

\section{Ovarian Stimulation Protocol}

The natural cycle was administered in females with regular menstrual cycles; IUI was performed based on the peak of the luteinizing hormone (LH), which was measured daily after the diameter of the follicle reached $16-18 \mathrm{~mm}$.
The ovulation induction cycle indications included the presence of an ovulation disorder, irregular menstruation, pregnancy failure after intercourse guided by vaginal ultrasound for monitoring natural cycle ovulation 2-3 times, small follicle ovulation (with a follicle diameter of $<15 \mathrm{~mm}$ ), and luteinized unruptured follicle syndrome. Ovulation induction was performed in accordance with the following protocol:

(a) Letrozole (LE): $2.5-5.0 \mathrm{mg} /$ day for 5 days starting from menstrual cycle day 3-5.

(b) Clomiphene citrate (CC): $50-100 \mathrm{mg} /$ day for 5 days starting from menstrual cycle day 3-5.

(c) LE + human menopausal gonadotropin (HMG): $2.5-5.0 \mathrm{mg} / \mathrm{day}$ for 5 days starting from menstrual cycle day $3-5$, followed by the addition of $37.5-$ 75.0 IU of HMG for a variable duration depending on the patient's response.

(d) $\mathrm{CC}+\mathrm{HMG}$ : $50-100 \mathrm{mg} /$ day for 5 days starting from menstrual cycle day $3-5$, followed by the addition of 37.5-75.0 IU of HMG for a variable duration depending on the patient's response.

(e) HMG: 37.5-75.0 IU/day for a variable duration depending on the response, starting from menstrual cycle day $3-5$.

\section{Operation Procedure}

A mature follicle with a diameter of $\geq 18 \mathrm{~mm}$ and EMT of $\geq 7 \mathrm{~mm}$, combined with the blood $\mathrm{LH}, \mathrm{E}_{2}$, and $\mathrm{P}$ values as well as the urine LH level were needed to determine whether to proceed with the injection of either urinary human chorionic gonadotrophin (hCG) or gonadotropin releasing hormone agonist (GnRH- $\alpha$ ) as well as to determine the injection dosage. The insemination was performed at $36-40 \mathrm{~h}$ after the injection of either hCG or GnRH- $\alpha$. Artificial insemination timing: (a) ovulation after single IUI; (b) ovulation before single IUI; (c) double IUI before and after ovulation (the ovulation was observed within the next day of the first IUI); and (d) double IUI before and after ovulation (the ovulation was observed after the next day of the first IUI). The washed semen sample was introduced into the woman's uterus using a syringe.

\section{Semen Processing}

Semen was collected via masturbation after an abstinence of 2-7 days and prepared post-liquefaction with two-layer density gradient centrifugation. In the case of abnormal liquefaction, the sperm was diluted with the same volume 
of culture medium and treated with density gradient centrifugation. Next, $1.5 \mathrm{~mL}$ of $90 \%$ solution (SpermGrad ${ }^{\mathrm{TM}}$ Lower Layer, Vitrolife, Sweden) was pipetted into the tube; $1.5 \mathrm{~mL}$ of $45 \%$ solution (SpermGrad ${ }^{\mathrm{TM}}$ Upper Layer, Vitrolife, Sweden) was then slowly dripped on top of the solution. Finally, the semen was gently layered on top. The tube was centrifuged at $300 \mathrm{~g}$ for 20 minutes, and the two top layers were removed. With as little of $90 \%$ solution (SpermGrad ${ }^{\mathrm{TM}}$ Lower Layer, Vitrolife, Sweden) as possible, the sperm pellet was transferred to a sterile conical tube with $5 \mathrm{~mL}$ of equilibrated G-IVF PLUS (Vitrolife, Sweden). The sperm sample was centrifuged at $300 \mathrm{~g}$ for 10 minutes, the supernatant discarded, and sperm repeatedly washed. The volume of the sample used for insemination was $0.3-0.5 \mathrm{~mL}$. The sample was assessed for motility and concentration.

\section{Luteal Phase Support}

Luteal phase support, consisting of dydrogesterone tablets (20-40 mg/day, po) or progesterone $(20-40 \mathrm{mg} /$ day, im) for 14 days, was routinely provided for all patients starting from the day of IUI performance. In patients with lowerthan-normal pre-ovulation estrogen levels or an EMT of $>8 \mathrm{~mm}$, progynova (1-2 mg/day, po) treatment was administered. A blood test for the hCG assay was performed at 14 days after insemination in order to confirm pregnancy occurrence. In women with a positive hCG, an ultrasound examination was performed at seven weeks of gestation to confirm fetal viability. Ultrasonography, among others, is evidence for determining clinical pregnancy.

\section{Statistical Indicators}

The measured variables included the respective rates of clinical pregnancy, biochemical pregnancy, and clinical pregnancy abortion. The definition of clinical pregnancy was gestation sac ultrasound visibility after four to five weeks of IUI; the clinical pregnancy rate is the proportion of these numbers to the total number of cycles. Biochemical pregnancy referred to a hCG value of $>25 \mathrm{mIU} / \mathrm{L}$ after $14-16$ days of IUI; the biochemical pregnancy rate was the proportion of these numbers to the total number of cycles. Clinical pregnancy abortion was a miscarriage after the ultrasound detection of a gestation sac; the clinical pregnancy abortion rate was the proportion of these numbers to the total clinical pregnancy number.

\section{Statistical Analysis}

Statistical evaluations were conducted using the Statistical Package for Social Sciences (SPSS) 17.0 software (SPSS Inc., Chicago, IL, USA). The measurement data were expressed as mean \pm standard deviation (SD) and evaluated using the independent-samples $t$-test. The enumeration data were expressed in percentage (\%) and evaluated using the Chi-square test. The level of significance was set at $\mathrm{p}<0.05$.

\section{Results}

The present retrospective cohort study included a total of 3984 cycles in 1862 couples. The characteristics of patients undergoing all cycles with IUI are presented in Table 1. Overall, the clinical pregnancy rate was $16.3 \%$ (649/3984), the biochemical pregnancy rate was $19.3 \%$ (770/3984), the clinical pregnancy abortion rate was $15.4 \%(100 / 649)$, and the ectopic pregnancy rate was $1.8 \%(12 / 649)$.

\section{Female Age}

The average female subject age was significantly lower in the clinical pregnant group $(28.97 \pm 4.06$ years $)$ than in the non-pregnant group $(30.47 \pm 4.84$ years $)(p<0.05)$ (Table 2). Based on age, the female study subjects were divided into three groups: (1) group a: aged $<25$ years; (2) group b: aged 25-35 years; and (3) group c: aged $>35$ years. A significant decrease in clinical pregnancy rate with age was found $(23.8 \%, 16.3 \%$, and $8.8 \%$, respectively; $\mathrm{p}=0.000$ ) (Table 3 ). The pairwise comparison results for the three groups showed statistically significant differences $(\mathrm{p}<0.05)$ (Table 3).

Table I Characteristics of Patient Undergoing All Cycles with IUI

\begin{tabular}{|l|c|}
\hline Variable & Mean \pm SD \\
\hline Female age (year) & $30.30 \pm 4.82$ \\
Male age (year) & $31.08 \pm 4.95$ \\
Body mass index $\left(\mathrm{kg} / \mathrm{m}^{2}\right)$ & $23.69 \pm 3.7 \mathrm{I}$ \\
Infertility years (year) & $3.19 \pm 2.20$ \\
Baseline FSH (IU/L) & $6.92 \pm 2.95$ \\
Baseline LH (IU/L) & $6.27 \pm 2.85$ \\
Baseline estrogen (pmol/L) & $144.85 \pm 100.2 \mathrm{I}$ \\
Baseline T (nmol/L) & $1.33 \pm 3.23$ \\
Baseline PRL (mlU/L) & $392.36 \pm 249.9 \mathrm{I}$ \\
\hline
\end{tabular}


Table 2 Comparison of the Female Age, Male Age, Endometrial Thickness on IUI Day and PTMC Between Pregnant Group and NonPregnant Group

\begin{tabular}{|l|c|c|c|c|}
\hline & Female Age $(\mathbf{y})$ & Male Age $(\mathbf{y})$ & Endometrial Thickness $(\mathbf{m m})$ & PTMC $\left(\times 10^{6} / \mathbf{m L}\right)$ \\
\hline Non-pregnant group & $30.47 \pm 4.84$ & $31.28 \pm 5.00$ & $10.25 \pm 2.10$ & $17.89 \pm 14.57$ \\
Pregnant group & $28.97 \pm 4.06$ & $29.84 \pm 4.31$ & $10.46 \pm 2.02$ & $19.54 \pm 16.14$ \\
T value & 8.468 & 7.229 & -2.253 & -2.638 \\
P value & 0.000 & 0.000 & 0.026 & 0.009 \\
\hline
\end{tabular}

\section{Male Age}

The average male subject age was significantly lower in the clinical pregnant group than in the non-pregnant group $(29.84 \pm 4.31$ years and $31.28 \pm 5.00$ years, respectively; $\mathrm{p}=0.000$ ) (Table 2). Based on age, the male study subjects were divided into three groups: (1) group a: subjects aged $<25$ years; (2) group b: subjects aged 25-35 years; and (3) group c: subjects aged $>35$ years. The clinical pregnancy rates were compared among the different groups $(23.8 \%$, $16.6 \%$, and $10.1 \%$, respectively); the differences were statistically significant $(\mathrm{p}=0.000)$ (Table 3$)$. The pairwise comparison results for the three groups showed that the differences were statistically significant $(p<0.05)$ (Table 3$)$.

\section{EMT on IUI Day}

The EMT was significantly thicker in the clinical pregnant group than in the control group $(10.46 \pm 2.02 \mathrm{~mm}$ and $10.25 \pm 2.10 \mathrm{~mm}$, respectively; $\mathrm{p}<0.05$ ) (Table 2). Based on EMT, the cases were divided into three groups: (1) group a: $<8 \mathrm{~mm}$; (2) group b: $8-12 \mathrm{~mm}$; and (3) group $\mathrm{c}:>12 \mathrm{~mm}$. The clinical pregnancy rate differences among the three groups $(13.5 \%, 17.0 \%$, and $17.0 \%$, respectively) were not statistically significant $(\mathrm{p}=0.054)$ (Table 4$)$. The pairwise comparison results for the three groups showed that the clinical pregnancy rate was significantly higher in group $b$ than in group $a(p=0.018)$ (Table 4$)$.

\section{Sperm Parameters}

The post-wash total motile sperm count (PTMC) of semen injected into the uterine cavity was $19.54 \pm 16.14 \times 10^{6} / \mathrm{mL}$ in the clinical pregnant group and $17.89 \pm 14.57 \times 10^{6} / \mathrm{mL}$ in the non-pregnant group; the difference was statistically significant $(\mathrm{p}<0.05)$ (Table 2$)$. Based on the PTMC, the cases were divided into four groups: (1) group a: $<5 \times 10^{6} / \mathrm{mL} ;(2)$ group b: $5-10 \times 10^{6} / \mathrm{mL}$; (3) group c: $10-20 \times 10^{6} / \mathrm{mL}$; and (4) group d: $>20 \times 10^{6} / \mathrm{mL}$. There were no significant differences in clinical pregnancy rates among the groups $(14.8 \%, 14.4 \%$, $17.3 \%$, and $17.3 \%$, respectively; $p=0.161$ ) (Table 4 ).

\section{Artificial Insemination Timing}

The clinical pregnancy rate difference between single IUI per cycle (12.1\%) and double IUI per cycle (17.8\%) was statistically significant $(\mathrm{p}<0.01)$ (Table 5$)$. Based on the IUI timing, the cases were divided into four groups: (1) group a: ovulation after single IUI; (2) group b: ovulation before single IUI; (3) group c: double IUI before and after ovulation (the ovulation was observed within the second day of the first IUI); and (4) group d: double IUI before and after ovulation (the ovulation was observed after the second day of the first IUI). Furthermore, there were significant differences in the clinical pregnancy rates among the groups $(11.9 \%, 11.9 \%, 18.7 \%$, and $11.9 \%$, respectively; $\mathrm{p}=$ 0.000 ) (Table 5). The pairwise comparison results for these

Table 3 The Clinical Pregnancy Rate According to Female Age and Male Age

\begin{tabular}{|c|c|c|c|c|c|c|}
\hline & \multicolumn{3}{|c|}{ Female Age (y) } & \multicolumn{3}{|c|}{ Male Age (y) } \\
\hline & $<25$ (a) & $25-35$ (b) & $>35$ (c) & $<25$ (a) & 25-35 (b) & $>35$ (c) \\
\hline Non-pregnant group & $44 \mid(76.2 \%)$ & 2355 (83.7\%) & 540 (91.2\%) & $320(76.2 \%)$ & 2410 (83.4\%) & 605 (89.9\%) \\
\hline Pregnant Group & I 38 (23.8\%) & $458(16.3 \%)$ & $52(8.8 \%)$ & $100(23.8 \%)$ & $48 \mathrm{I}(16.6 \%)$ & $68(10.1 \%)$ \\
\hline$\chi^{2}$ value & \multicolumn{3}{|c|}{48.628} & \multicolumn{3}{|c|}{36.557} \\
\hline$P$ value & \multicolumn{3}{|c|}{0.000} & \multicolumn{3}{|c|}{0.000} \\
\hline
\end{tabular}

Notes: Pairwise comparison in female age group $\left[\chi^{2}(P)\right] . P<0.05$ : a: b $18.709(0.000)$; a: c $48.779(0.000)$; b: c $27.760(0.000)$. Pairwise comparison in male age group $\left[\chi^{2}(P)\right]$. $P<0.05$ : a: b 13.036 (0.000); a: c 37.344 (0.000); b: c $17.885(0.000)$ 
Table 4 The Clinical Pregnancy Rate According to Endometrial Thickness on IUI Day and PTMC

\begin{tabular}{|c|c|c|c|c|c|c|c|}
\hline & \multicolumn{3}{|c|}{ Endometrial Thickness (mm) } & \multicolumn{4}{|c|}{ PTMC $\left(\times 10^{6} / \mathrm{mL}\right)$} \\
\hline & $<8$ (a) & $8-12$ (b) & $>12$ (c) & $<5$ (a) & $5-10$ (b) & $10-20$ (c) & $>20$ (d) \\
\hline Non-pregnant group & $688(86.5 \%)$ & $2175(83.0 \%)$ & $472(83.0 \%)$ & $553(85.2 \%)$ & $692(85.6 \%)$ & 949 (82.7\%) & $|I 4|(82.7 \%)$ \\
\hline Pregnant group & $107(13.5 \%)$ & 445 (I7.0\%) & 97 (I7.0\%) & $96(14.8 \%)$ & $116(14.4 \%)$ & 199 (17.3\%) & $238(I 7.3 \%)$ \\
\hline$\chi^{2}$ value & \multicolumn{3}{|c|}{5.839} & \multicolumn{4}{|c|}{5.151} \\
\hline$P$ value & \multicolumn{3}{|c|}{0.054} & \multicolumn{4}{|c|}{0.161} \\
\hline
\end{tabular}

Notes: Pairwise comparison in Endometrial thickness group $\left[\chi^{2}(P)\right]$. $P<0.05$ : a: b 5.595 (0.018); $P>0.05$ : a: c 3.357 (0.076); b: c 0.001 (0.95I). Pairwise comparison in PTMC group $\left[\chi^{2}(P)\right] . P>0.05$ : a: b 0.050 (0.823); a: c 1.953 (0.165); a: d I.952 (0.178); b: c 3.113 (0.080); b: d 3.164 (0.081); c: d 0.003 (0.958).

Table 5 The Clinical Pregnancy Rate According to the Frequency and Timing of IUI

\begin{tabular}{|c|c|c|c|c|c|c|}
\hline & \multicolumn{2}{|c|}{ The Frequency of IUI } & \multicolumn{4}{|c|}{ The Timing of IUI } \\
\hline & Single IUI (a) & Double IUI (b) & $\mathbf{a}$ & b & c & d \\
\hline Non-pregnant group & $946(87.8 \%)$ & $2389(82.2 \%)$ & $356(88.1 \%)$ & $589(87.8 \%)$ & $2063(81.3 \%)$ & $327(88.1 \%)$ \\
\hline Pregnant group & $13 \mid(12.1 \%)$ & $518(17.8 \%)$ & 48 (II.9\%) & $82(11.9 \%)$ & 475 (I8.7\%) & 44 (II.9\%) \\
\hline$\chi^{2}$ value & \multicolumn{2}{|c|}{18.433} & \multicolumn{4}{|c|}{30.197} \\
\hline$P$ value & \multicolumn{2}{|c|}{0.000} & \multicolumn{4}{|c|}{0.000} \\
\hline
\end{tabular}

Notes: The timing of IUI: a. Ovulation after a single IUI; b. Ovulation before a single IUI; c. double IUI before and after ovulation, and the ovulation was observed within the next day of the first IUI; $d$. double IUI before and after ovulation, and the ovulation was observed after the next day of the first IUI. Pairwise comparison $\left[\chi^{2}(P)\right]$. $P<0.05$ : a: c II.I37 (0.00I); b: c I5.607 (0.000); c: d 10.379 (0.00I). P>0.05: a: b 0.027 (0.923); a: d 0.000 (I.000); b: d 0.029 (0.92I).

four groups showed that the clinical pregnancy rate was significantly higher in group $\mathrm{c}$ than in the other three groups (group c/group a: $\mathrm{p}=0.001$; group c/group $\mathrm{b}: \mathrm{p}=0.000$; group c/group $\mathrm{d}: \mathrm{p}=0.001$ ) (Table 5).

\section{Ovarian Stimulation Protocol}

The present study cases included 2030 natural cycles and 1954 ovulation induction cycles. The clinical pregnancy rate was significantly higher in ovarian stimulation cycles than in natural cycles $(21.2 \%$ and $11.6 \%$, respectively; $\mathrm{p}<$ 0.01) (Table 6). Based on the medication scheme, the ovulation induction cycles were divided into five groups: (1) group a: LE; (2) group b: CC; (3) group c: LE+HMG; (4) group d: $\mathrm{CC}+\mathrm{HMG}$; and (5) group e: HMG. When we compared group a and c, group b and c, group a and $d$, group a and e, as well as group c and e respectively, we

Table 6 The Clinical Pregnancy Rate According to Treatment Protocol

\begin{tabular}{|c|c|c|c|c|c|c|c|}
\hline & \multicolumn{2}{|c|}{ Treatment Protocol } & \multicolumn{5}{|c|}{ Ovarian Stimulation Protocol } \\
\hline & $\begin{array}{l}\text { Natural } \\
\text { Cycle }\end{array}$ & $\begin{array}{l}\text { Ovarian Stimulation } \\
\text { Cycle }\end{array}$ & LE (a) & CC (b) & $\begin{array}{l}\text { LE+HMG } \\
\text { (c) }\end{array}$ & $\begin{array}{c}\text { CC+HMG } \\
\text { (d) }\end{array}$ & HMG (e) \\
\hline $\begin{array}{l}\text { Non-pregnant } \\
\text { group }\end{array}$ & $1795(88.4 \%)$ & $1540(78.8 \%)$ & $263(86.5 \%)$ & $94(86.2 \%)$ & 476 (72.9\%) & $104(78.2 \%)$ & $603(79.9 \%)$ \\
\hline Pregnant group & $235(11.6 \%)$ & $414(21.2 \%)$ & $4 I(13.5 \%)$ & $15(13.8 \%)$ & 177 (27.1\%) & $29(21.8 \%)$ & $152(20.1 \%)$ \\
\hline$\chi^{2}$ value & \multicolumn{2}{|r|}{67.442} & \multicolumn{5}{|c|}{28.626} \\
\hline$P$ value & \multicolumn{2}{|r|}{0.000} & \multicolumn{5}{|c|}{0.000} \\
\hline
\end{tabular}

Notes: Pairwise comparison $\left[\chi^{2}(P)\right]$. P<0.05: a: c 21.87। (0.000); b: c 8.825 (0.003); a: d 4.758 (0.034); a: e 6.423 (0.01 I); c: e 9.508 (0.002). P>0.05: a: b 0.005 (I.000); b: e 2.479 (0.12I); c: d I.606 (0.234); d: e 0.195 (0.642); b: d 2.605 (0.132). 
found that different ovarian stimulation protocols related to the pregnancy outcome $(\mathrm{P}<0.05)$ (Table 6$)$. The clinical pregnancy rate in group $\mathrm{c}$ was the highest when compared with the other groups. The pairwise comparison results for the five groups showed that the clinical pregnancy rate was significantly higher in group $\mathrm{c}$ than in groups $\mathrm{a}, \mathrm{b}$, and $\mathrm{e}$ (group c/group a: $\mathrm{p}=0.000$; group c/group $\mathrm{b}: \mathrm{p}=0.003$; group c/group e: $\mathrm{p}=0.002)($ Table 6$)$.

\section{Discussion}

As a type of ART, IUI increases the conception rate. Determining how to improve the clinical pregnancy rate has been a common topic among researchers and can be discussed in regard to the following aspects.

\section{Female Age}

In previous studies, it was found that age in female subjects is an important factor affecting the clinical pregnancy rate; the clinical pregnancy rate gradually decreases with the increase in age. ${ }^{7-11}$ The conclusion of the present study is consistent with these views; the data revealed that female subjects were significantly younger in the pregnant group than in the non-pregnant group. Furthermore, when compared with other age groups, female subjects aged $<25$ years had the highest clinical pregnancy rate; the differences were statistically significant $(p<0.05)$. With the increase in female subject age, especially upon reaching $>35$ years, the oocyte number becomes rapidly exhausted. Subsequently, metabolite accumulation in the body changes the ovarian environment, resulting in deoxyribonucleic acid mutations and telomere shortening, for instance; this leads to a physiological decline in oocyte quality. ${ }^{12}$ Moreover, endometrial receptivity is gradually reduced with the increase in age; thus, delaying implantation in endometrial window extremes can result in poor pregnancy outcomes. ${ }^{13}$ All of the above-listed factors increase the chances of infertility.

\section{Male Age}

In a present study, Zhang ${ }^{7}$ found that the clinical pregnancy rate was higher in male subjects aged $<30$ years than in male subjects aged $>30$ years; however, the difference was not statistically significant. The data processed in the present study revealed that male subjects were significantly younger in the pregnant group than in the non-pregnant group. Furthermore, the clinical pregnancy rate in the group with subjects aged $<25$ years was the highest among the different age groups, and the clinical pregnancy rate significantly declined with age; Govindarajan ${ }^{8}$ came to the same conclusion. Male age mainly affects pregnancy outcomes through sperm quality influence. It has been found that, in male subjects, sperm volume, concentration, and vitality all decrease with the increase in age ${ }^{14-16}$ while the malformation rate increases. ${ }^{15,16}$ However, Nijs ${ }^{17}$ did not detect the effects of subject age on sperm concentration, movement, and morphology. Therefore, the effects of age in male subjects on the pregnancy outcome requires further exploration.

\section{Sperm Parameters}

There are different opinions regarding the impact of PTMC on the clinical pregnancy rate. Lemmens ${ }^{18}$ considers PTMC to have no predictive value in the artificial insemination pregnancy outcome; it is more likely to be predicted using the total motile sperm count. ${ }^{18-20}$ The data included in the present study has revealed that the PTMC was significantly higher in the pregnancy group than in the non-pregnancy group. However, no significant reduction in clinical pregnancy rate was found with a PTMC of $<5 \times 10^{6} / \mathrm{mL}$. Furthermore, male patients with mild asthenospermia are the most appropriate subjects to receive this treatment; however, when sperm activity declines further, reaching a sufficient sperm concentration is difficult. At this point, there must be other factors affecting the pregnancy outcome. An expanded sample size would help confirm this regularity in future investigations.

\section{EMT}

A large number of studies have shown that the ART pregnancy outcome is affected by the EMT on the day of IUI performance. ${ }^{21,22}$ De Geyter ${ }^{22}$ considers EMT an independent factor affecting the clinical pregnancy rate, and Zhang $^{7}$ considers the clinical pregnancy rate to be highest with an EMT of 8-12 $\mathrm{mm}$. The results of the present study reveal that subject EMT was thicker in the clinical pregnancy group than in the non-pregnancy group; however, the difference was too small. When the cases were divided into three groups based on EMT on the day of IUI (group 1: $<8 \mathrm{~mm}$; group 2: $8-12 \mathrm{~mm}$; and group 3: $>12 \mathrm{~mm}$ ), it was found that the clinical pregnancy rate was higher in group 2 than in group 1; however, this was similar to the clinical pregnancy rate in group 3 . Weissman et $\mathrm{al}^{23}$ found that the implantation and pregnancy rates were higher during an EMT of 7-14 $\mathrm{mm}$ than an EMT of $>14 \mathrm{~mm}$. Zhao et $\mathrm{al}^{24}$ reported that the clinical pregnancy rate during an EMT of $>7 \mathrm{~mm}$ was significantly higher than during 
an EMT of $<7 \mathrm{~mm}$. Overall, a thin endometrium may decline the clinical pregnancy and lower the implantation rate. Moffat et $\mathrm{al}^{25}$ also reported that age in female subjects, decreased ovarian reserve, endometriosis, and the hypogonadotrophic hormone all affect EMT. In addition to a thin endometrium, low implantation and pregnancy rates may be caused by other prognostic factors, such as age, endometrium pattern, inflammation, and endocrine disorders, all of which affect endometrial receptivity. Hence, the effects of EMT on the pregnancy rate require further study.

\section{IUI Timing and Frequency}

The success of an IUI is significantly correlated with the mastery of IUI timing and frequency. The present research data have revealed that the clinical pregnancy rate was significantly higher in double IUI per cycle than in single IUI per cycle. Ragni ${ }^{26}$ also considered the pregnancy outcome to be better in double IUI per cycle than in single IUI per cycle. In the double IUI cycles, the first IUI was implemented before ovulation and the second IUI after ovulation. During the ovulation observed over the next day of the first IUI, the clinical pregnancy rate was higher than the during the ovulation observed after the next day of the first IUI. Several studies ${ }^{27,28}$ have considered that, in single IUI cycles, post-ovulation IUI can significantly improve the pregnancy outcome when compared to pre-ovulation IUI. The data included in the present study have revealed that the clinical pregnancy rate was higher in post-ovulation IUI than in pre-ovulation IUI. However, the difference was not statistically significant $(p$ $>0.05)$. The IUI treatment rationale is to increase the couple conception rate by increasing the chance of the maximum number of healthy sperm reaching the fertilization site. The fertilization ability of sperm can be maintained for approximately 12 hours, and the oocytes can survive for 24-48 hours in vivo. ${ }^{29}$ Therefore, the closer the IUI timing is to the ovulation, the more spermatozoa enter into the female body, thus increasing the pregnancy rate.

\section{Ovarian Stimulation Protocol}

There are different opinions regarding the effects of different treatment protocols on the clinical pregnancy outcome. In previous studies, certain scholars ${ }^{7,30-32}$ presented no significant clinical pregnancy rate difference between the ovarian stimulation cycle and the natural cycle. However, other studies ${ }^{9,33,34}$ have considered the ovarian stimulation scheme to significantly improve the clinical pregnancy rate, as opposed to the natural scheme. In addition, several studies have demonstrated that, in IUI programs, cycles with $\mathrm{HMG}$ are associated with better reproductive outcomes than cycles with $\mathrm{CC}^{35,36}$ and LE. $^{35}$ The data in the present study has revealed that the clinical pregnancy rate was significantly higher in the ovarian stimulation cycle than in the natural cycle $(\mathrm{p}<$ 0.05). On the one hand, the use of ovarian stimulation drugs can make up for sperm factor defects; ${ }^{37}$ on the other hand, determining the most appropriate insemination time is difficult due to the natural cycle's unstable LH peak fluctuation. However, while the artificial insemination timing in the natural cycle is inaccurate, ovarian stimulation application would make ovulation time estimation easier. The clinical pregnancy rate was higher in the HMG group than in the non-HMG groups in different ovarian stimulation protocols (Table 5). Furthermore, the LE + HMG group had the highest clinical pregnancy rate, while the CC group had the lowest clinical pregnancy rate. Furthermore, it was found that the clinical pregnancy rate in the $\mathrm{CC}$ group and LE group was similar to the rate in the natural cycle group. Dinelli ${ }^{11}$ also considered the single CC use unable to improve the clinical pregnancy rate in unexplained subfertility. This may be associated with CC's anti-estrogen effect on the endometrium. Most patients only have single follicle development when $\mathrm{CC}$ is used alone. However, the follicle number can be appropriately increased by combining $\mathrm{CC}$ with $\mathrm{HMG}$, thereby increasing the estrogen level, increasing EMT, and improving the clinical pregnancy rate to a certain extent. LE is a third-generation aromatase inhibitor in which negative feedback increases the pituitary follicle stimulating hormone (FSH) release by inhibiting estrogen synthesis, thereby promoting follicle growth and development. ${ }^{38}$ HMG is a commonly used gonadotropin in clinical practice. Its commercial preparation contains $75 \mathrm{U}$ of FSH and $75 \mathrm{U}$ of LH per ampoule. ${ }^{39}$ FSH can enhance follicular recruitment and growth during folliculogenesis as well as increase the estrogen level and promote endometrial proliferation. ${ }^{40}$ The negative feedback effect on FSH increased more in the LE+HMG group than in the HMG group. Hence, the pregnancy rate was higher in the LE+HMG group than in the HMG group.

\section{Conclusion}

In conclusion, fertility is greatly reduced at an age of $>35$ years, regardless of gender. It has been suggested that the 
reproductive age should be reasonably arranged. The clinical pregnancy rate becomes higher with the increase in PTMC. It is noteworthy that a good pregnancy outcome can also be obtained with a PTMC of $<5 \times 10^{6} / \mathrm{mL}$. In addition, the ovarian stimulation scheme is a good choice for obtaining a satisfactory pregnancy outcome as soon as possible; the LE+HMG scheme is ideal. Meanwhile, combining this scheme with double IUI before and after ovulation, especially when the ovulation is observed within the next day of the first IUI, would greatly improve the chances of pregnancy.

\section{Acknowledgments}

We are particularly grateful to all the people who have given us help on our article.

\section{Funding}

The present study was supported by the Medical Science and Technology development Program of Shandong Province (grant no. 2011QZ002 to Q. C. Li) and Shandong Natural Science Foundation (grant no. ZR2012HL03 to Y. L. Wang and grant no. ZR2017LH013 to H. L. Sun).

\section{Disclosure}

The authors declare that they have no competing interests.

\section{References}

1. Abdelkader AM, Yeh J. The potential use of intrauterine insemination as a basic option for infertility: a review for technology-limited medical settings. Obstet Gynecol Int. 2009;2009:584837. doi:10.1155/ 2009/584837

2. Tang Y, He QD, Zhang TT, Wang JJ, Huang SC, Ye Y. Controlled ovarian stimulation should not be preferred for male infertility treated with intrauterine insemination: a retrospective study. Reprod Biol Endocrinol. 2021;19:45. doi:10.1186/s12958-021-00730-3

3. ESHRE Capri Workshop Group. Intrauterine insemination. Hum Reprod Update. 2009;15:265-277. doi:10.1093/humupd/dmp003

4. Peterson CM, Hatasaka HH, Jones KP, Poulson AM Jr, Carrell DT, Urry RL. Ovulation induction with gonadotropins and intrauterine insemination compared with in vitro fertilization and no therapy: a prospective, nonrandomized, cohort study and meta-analysis. Fertil Steril. 1994;62:535-544. doi:10.1016/S0015-0282(16)56942-8

5. Calhaz-Jorge C, De GC, Kupka MS, et al.; European IVF-monitoring Consortium (EIM); European Society of Human Reproduction and Embryology (ESHRE). Assisted reproductive technology in Europe, 2013: results generated from European registers by ESHRE. Hum Reprod. 2017;32:1957-1973. doi:10.1093/humrep/dex264

6. Fauser BC, Nargund G, Andersen AN, et al. Mild ovarian stimulation for IVF: 10 years later. Hum Reprod. 2010;25:2678-2684. doi:10.1093/humrep/deq247

7. Zhang K, Shi Y, Wang E, et al. Ovarian stimulated cycle: not a better alternative for women without ovulation disorder in intrauterine insemination. Oncotarget. 2017;8:100773-100780. doi:10.18632/ oncotarget. 22052
8. Govindarajan M, Mallikarjunan S, Ahmed HSR, et al. Retrospective study of factors affecting intrauterine insemination pregnancy outcome: the impact of male habits and working environment. J Hum Reprod Sci. 2017;10:114-118. doi:10.4103/ jhrs.JHRS_3_17

9. Thijssen A, Creemers A, Van der Elst W, et al. Predictive factors influencing pregnancy rates after intrauterine insemination with frozen donor semen: a prospective cohort study. Reprod Biomed Online. 2017;34:590-597. doi:10.1016/j.rbmo.2017.03.012

10. Hansen KR, He AL, Styer AK, et al. Eunice Kennedy Shriver National Institute of Child Health and Human Development Reproductive Medicine Network. Predictors of pregnancy and live-birth in couples with unexplained infertility after ovarian stimulation-intrauterine insemination. Fertil Steril. 2016;105:1575-1583. doi:10.1016/j.fertnstert.2016.02.020

11. Dinelli L, Courbière B, Achard V, et al. Prognosis factors of pregnancy after intrauterine insemination with the husband's sperm: conclusions of an analysis of 2019 cycles. Fertil Steril. 2014;101:994-1000. doi:10.1016/j.fertnstert.2014.01.009

12. Keefe DL, Marquard K, Liu L. The telomere theory of reproductive senescence in women. Curr Opin Obstet Gynecol. 2006;18:280-285. doi:10.1097/01.gco.0000193019.05686.49

13. He A, Zou Y, Wan C, et al. The role of transcriptomic biomarkers of endometrial receptivity in personalized embryo transfer for patients with repeated implantation failure. J Transl Med. 2021;19:176. doi:10.1186/s12967-021-02837-y

14. Kidd SA, Eskenazi B, Wyrobek AJ. Effects of male age on semen quality and fertility: a review of the literature. Fertil Steril. 2001;75:237-248. doi:10.1016/S0015-0282(00)01679-4

15. Eskenazi B, Wyrobek AJ, Sloter E, et al. The association of age and semen quality in healthy men. Hum Reprod. 2003;18:447-454. doi:10.1093/humrep/deg107

16. Levitas E, Lunenfeld E, Weisz N, Friger M, Potashnik G. Relationship between age and semen parameters in men with normal sperm concentration: analysis of 6022 semen samples. Andrologia. 2007;39:45-50. doi:10.1111/j.1439-0272.2007.00761.x

17. Nijs M, De Jonge C, Cox A, Janssen M, Bosmans E, Ombelet W. Correlation between male age, WHO sperm parameters, DNA fragmentation, chromatin packaging and outcome in assisted reproduction technology. Andrologia. 2011;43:174-179. doi:10.1111/j.14390272.2010.01040.x

18. Lemmens L, Kos S, Beijer C, et al. Semen Section of the Dutch Foundation for Quality Assessment in Medical Laboratories. Predictive value of sperm morphology and progressively motile sperm count for pregnancy outcomes in intrauterine insemination. Fertil Steril. 2016;105:1462-1468. doi:10.1016/j. fertnstert.2016.02.012

19. Hamilton JA, Cissen M, Brandes M, et al. Total motile sperm count: a better indicator for the severity of male factor infertility than the WHO sperm classification system. Hum Reprod. 2015;30:1110-1121. doi:10.1093/humrep/dev058

20. Yalti S, Gürbüz B, Sezer H, Celik S. Effects of semen characteristics on IUI combined with mild ovarian stimulation. Arch Androl. 2004;50:239-246. doi:10.1080/01485010490448435

21. Yuan X, Saravelos SH, Wang Q, Xu Y, Li TC, Zhou C. Endometrial thickness as a predictor of pregnancy outcomes in 10787 fresh IVF-ICSI cycles. Reprod Biomed Online. 2016;33:197-205. doi:10.1016/j.rbmo.2016.05.002

22. De Geyter C, Schmitter M, De Geyter M, Nieschlag E, Holzgreve W, Schneider HP. Prospective evaluation of the ultrasound appearance of the endometrium in a cohort of 1186 infertile women. Fertil Steril. 2000;73:106-113. doi:10.1016/S0015-0282(99)00484-7

23. Weissman A, Gotlieb L, Casper RF. The detrimental effect of increased endometrial thickness on implantation and pregnancy rates and outcome in an in vitro fertilization program. Fertil Steril. 1999;71:147-149. doi:10.1016/S0015-0282(98)00413-0 
24. Zhao J, Zhang Q, Li Y. The effect of endometrial thickness and pattern measured by ultrasonography on pregnancy outcomes during IVF-ET cycles. Reprod Biol Endocrinol. 2012;10:100. doi:10.1186/ 1477-7827-10-100

25. Moffat R, Beutler S, Schötzau A, De Geyter M, De Geyter C. Endometrial thickness influences neonatal birth weight in pregnancies with obstetric complications achieved after fresh IVF-ICSI cycles. Arch Gynecol Obstet. 2017;296:115-122.

26. Ragni G, Somigliana E, Vegetti W. Timing of intrauterine insemination: where are we? Fertil Steril. 2004;82:25-26. doi:10.1016/j. fertnstert.2004.01.028

27. Kucuk T. Intrauterine insemination: is the timing correct? J Assist Reprod Genet. 2008;25:427-430. doi:10.1007/s10815-008-9247-9

28. Ghanem ME, Bakre NI, Emam MA, et al. The effects of timing of intrauterine insemination in relation to ovulation and the number of inseminations on cycle pregnancy rate in common infertility etiologies. Hum Reprod. 2011;26:576-583. doi:10.1093/humrep/deq362

29. Edwards RG, Brody SA. Principles and Practice of Assisted Human Reproduction. 1st ed. Philadelphia: W.B. Saunders; 1995.

30. Ferrara I, Balet R, Grudzinskas JG. Intrauterine insemination with frozen donor sperm. Pregnancy outcome in relation to age and ovarian stimulation regime. Hum Reprod. 2002;17:2320-2324. doi:10.1093/humrep/17.9.2320

31. Botchan A, Hauser R, Gamzu R, Yogev L, Paz G, Yavetz H. Results of 6139 artificial insemination cycles with donor spermatozoa. Hum Reprod. 2001;16:2298-2304. doi:10.1093/humrep/16.11.2298

32. De Brucker M, Haentjens P, Evenepoel J, Devroey P, Collins J, Tournaye H. Cumulative delivery rates in different age groups after artificial insemination with donor sperm. Hum Reprod. 2009;24:1891-1899. doi:10.1093/humrep/dep085

33. Farquhar CM, Liu E, Armstrong S, Arroll N, Lensen S, Brown J. Intrauterine insemination with ovarian stimulation versus expectant management for unexplained infertility (TUI): a pragmatic, open-label, randomised, controlled, two-centre trial. Lancet. 2018;391:441-450. doi:10.1016/S0140-6736(17)32406-6
34. Zuzuarregui JL, Meseguer M, Garrido N, Simón C, Pellicer A, Remohí J. Parameters affecting the results in a program of artificial insemination with donor sperm. A 12-year retrospective review of more than 1800 cycles. J Assist Reprod Genet. 2004;21:109-118. doi:10.1023/B:JARG.0000029494.55273.a2

35. Diamond MP, Legro RS, Coutifaris C, et al. NICHD reproductive medicine network. letrozole, gonadotropin, or clomiphene for unexplained infertility. N Engl J Med. 2015;373:1230-1240. doi:10.1056/ NEJMoa1414827

36. Peeraer K, Debrock S, De Loecker P, et al. Low-dose human menopausal gonadotrophin versus clomiphene citrate in subfertile couples treated with intrauterine insemination: a randomized controlled trial. Hum Reprod. 2015;30:1079-1088. doi:10.1093/humrep/dev062

37. Francavilla F, Sciarretta F, Sorgentone S, et al. Intrauterine insemination with or without mild ovarian stimulation in couples with male subfertility due to oligo/astheno- and/or teratozoospermia or antisperm antibodies: a prospective cross-over trial. Fertil Steril. 2009;92:1009-1011. doi:10.1016/j.fertnstert.2009.01.112

38. Zhang S, Lian F. [The clinical application of Letrozole in male or female infertility and OHSS]. World Latest Med Inf. 2016;16:5860,74. [In Chinese]

39. Wu YL, Zhang Y, Tang LM, et al. [Establishment of the proposed 4th national standard reference for human menopausal gonadotropin (HMG)]. Chin J Pharm Anal. 2016;36:1487-1494. [In Chinese].

40. Busch AS, Hagen CP, Almstrup K, Main KM, Juul A. Genetic variations altering FSH action affect circulating hormone levels as well as follicle growth in healthy peripubertal girls. Hum Reprod. 2016;31:897-904. doi:10.1093/humrep/dew022
International Journal of General Medicine

\section{Publish your work in this journal}

The International Journal of General Medicine is an international, peer-reviewed open-access journal that focuses on general and internal medicine, pathogenesis, epidemiology, diagnosis, monitoring and treatment protocols. The journal is characterized by the rapid reporting of reviews, original research and clinical studies
Dovepress

across all disease areas. The manuscript management system is completely online and includes a very quick and fair peer-review system, which is all easy to use. Visit http://www.dovepress.com/ testimonials.php to read real quotes from published authors. 